\title{
Multicomponent nanoparticles as nonviral vectors for the treatment of Fabry disease by gene therapy
}

This article was published in the following Dove Press journal:

Drug Design, Development and Therapy

25 October 2012

Number of times this article has been viewed

\author{
Aritz Pérez Ruiz de Garibay \\ Diego Delgado \\ Ana del Pozo-Rodríguez \\ María Ángeles Solinís \\ Alicia Rodríguez Gascón \\ Pharmacokinetics, Nanotechnology \\ and Gene Therapy Group, Pharmacy \\ Faculty, University of the Basque \\ Country UPV/EHU, Vitoria-Gasteiz, \\ Spain
}

Purpose: Gene-mediated enzyme replacement is a reasonable and highly promising approach for the treatment of Fabry disease (FD). The objective of the present study was to demonstrate the potential applications of solid lipid nanoparticle (SLN)-based nonviral vectors for the treatment of FD.

Methods: SLNs containing the pR-M10- $\alpha$ Gal A plasmid that encodes the $\alpha$-Galactosidase A $(\alpha-G a l A)$ enzyme were prepared and their in vitro transfection efficacy was studied in Hep G2 cells. We also studied the cellular uptake of the vectors and the intracellular disposition of the plasmid.

Results: The enzymatic activity of the cells treated with the vectors increased significantly relative to the untreated cells, regardless of the formulation assayed. When the SLNs were prepared with protamine or dextran and protamine, the activity of the $\alpha$-Gal A enzyme by the transfected Hep G2 cells increased up to 12-fold compared to that of untreated cells.

Conclusion: With this work we have revealed in Hep G2 cells the ability of a multicomponent system based on SLNs to act as efficient nonviral vectors to potentially correct low $\alpha$-Gal A activity levels in FD with gene therapy.

Keywords: solid lipid nanoparticles, Fabry disease, nonviral vectors, gene therapy

\section{Introduction}

Fabry disease (FD) is an X-linked lysosomal storage disorder caused by an activitydeficient lysosomal hydrolase called $\alpha$-Galactosidase A ( $\alpha$-Gal A). ${ }^{1}$ The absence of sufficient enzymatic activity results in a systemic accumulation of neutral glycosphingolipids, predominantly globotriaosylceramide (Gb3), especially in endothelial cells and the smooth muscle cells of blood vessels. ${ }^{2}$ FD has a wide variety of clinical phenotypes. This spectrum ranges from the classic severe phenotype in males to an apparently asymptomatic disease observed in heterozygous females. Patients suffer progressive multiple organ pathology, including chronic neuropathic pain; gastrointestinal disturbances; angiokeratoma; and renal, cardiac, and cerebral complications that lead to premature mortality. ${ }^{3}$

At present, enzyme replacement therapy (ERT) is the only specific treatment available for FD. ERT has been reported to improve renal pathology and cardiac function, reduce the severity of neuropathic pain, and improve pain-related quality of life. ${ }^{3}$ The need for the early establishment of the treatment - prior to irreversible organ damage - and the potential production of anti- $\alpha$-Gal A antibodies are important disadvantages of ERT. ${ }^{4}$ Another important drawback, as with other recombinant therapies, is the financial cost of human $\alpha$-Gal A treatment. At the registered dose, the annual cost of
Correspondence: Alicia Rodríguez Gascón Pharmacy and Pharmaceutical Technology Laboratory, Pharmacy Faculty, University of the Basque Country (UPV/EHU), Paseo de la Universidad 7, 01006 Vitoria-Gasteiz, Spain Tel +34945013094

Email alicia.rodriguez@ehu.es 
the drug reaches approximately $€ 210,000$ per 70 -kg patient. ${ }^{5}$ To overcome these problems, several alternative therapies are being studied, including gene therapy. FD is an excellent candidate for gene therapy, as it corresponds to a single gene disorder and is not subject to complex regulation mechanisms; in addition, enzyme activity of only $15 \%-20 \%$ of the normal level is, in general, sufficient for clinical efficacy. ${ }^{6}$ Moreover, it offers long-term therapeutic effects, reduces the need for repeated administration, and is less expensive.

Most of the studies of gene therapy for FD have been carried out using viral vectors, with promising results. ${ }^{7-9}$ However, nonviral vectors are safer, cheaper, and more reproducible than viral vectors and have no restriction in the size of DNA they can carry. In particular, nonviral vectors based on cationic lipids such as solid liquid nanoparticle (SLN) have become a promising approach for gene delivery systems. In previous studies, we have already shown the ability of SLN for transfection both in vitro and in vivo. ${ }^{10-13}$

The objective of the present study was to demonstrate the ability of SLN-based nonviral vectors to increase $\alpha-G a l$ A activity levels in vitro. As part of our efforts to achieve this goal, we prepared SLN containing the pR-M10- $\alpha$ Gal A plasmid that encodes the $\alpha$-Gal A enzyme. We measured $\alpha$-Gal A activity in Hep G2 cells after in vitro transfection.

\section{Material and methods Preparation of vectors}

Two different plasmids were used depending on the aim of the assay. The pCMS-EGFP plasmid, encoding the EGFP (Clontech, Palo Alto, CA), and the pR-M10- $\alpha$ Gal A plasmid were purchased from Origene (Rockville, MD). Both plasmids were amplified by drobiosystems (San Sebastián, Spain). To prepare DNA-SLN vectors, a plasmid solution was mixed with an aqueous suspension of SLN prepared by a solvent emulsification-evaporation technique. ${ }^{14}$ ProtamineDNA-SLN vectors and dextran-protamine-DNA-SLN vectors were prepared as previously described by Delgado et al. ${ }^{15,16}$ The SLN-to-DNA ratio, expressed as the ratio of DNA to DOTAP (w:w), was fixed at 1:5 for the pCMS-EGFP plasmidcontaining vectors, and varied between 1:5 and 1:8 for the pR-M10- $\alpha$ Gal A-containing vectors.

\section{Size and superficial charge determination}

The sizes and superficial charges of vectors, diluted in Milli-Q ${ }^{\mathrm{TM}}$ (EMD Millipore, Billerica, MA) water, were determined on a Zetasizer Nano ZS (Malvern Instruments, Malvern, UK) by photon correlation spectroscopy and laser Doppler velocimetry, respectively.

\section{Binding, DNase I protection, and SDS-induced release of DNA}

Vectors in a $0.03 \mu \mathrm{g} \mathrm{DNA} / \mu \mathrm{L}$ concentration were subjected to electrophoresis on an ethidium bromide-containing gel (1\% agarose). Subsequently, bands were photographed with an Uvidoc D-55-LCD-20M Auto transilluminator (UVItec Limited, Cambridge, UK). In the protection study, Deoxyribonuclease I (DNase I) (Sigma-Aldrich, St Louis, MO) at a concentration of $1.5 \mathrm{U}$ DNase $\mathrm{I} / 2.5 \mu \mathrm{g}$ DNA was incubated $\left(37^{\circ} \mathrm{C}\right)$ with the vectors for 30 minutes. Afterward, a 1\% sodium lauryl sulfate (SDS) (Sigma-Aldrich) solution was added as a DNA release reagent. In addition, the vectors were mixed only with SDS to separately analyze the ability of DNA to be released. Samples were subjected to agarose gel electrophoresis and compared to untreated DNA. The gel electrophoresis materials were acquired from Bio-Rad Laboratories (Hercules, CA).

\section{Cell culture and transfection protocol}

For in vitro assays, human hepatocellular carcinoma (Hep G2) cells from the American Type Culture Collection ([ATCC] Manassas, VA) were used. Cells were maintained in Eagle's minimal essential medium (ATCC), supplemented with $10 \%$ fetal bovine serum (Life Technologies, Carlsbad, CA) and 1\% Normocin ${ }^{\mathrm{TM}}$ (InvivoGen, San Diego, CA). Cells were incubated at $37^{\circ} \mathrm{C}$ and $5 \% \mathrm{CO}_{2}$ and subcultured every 2-3 days. For pCMS-EGFP transfection, 120,000 cells per well were seeded on 24-well plates 24 hours before treating with the vectors, whereas for transfection with pR-M10- $\alpha \mathrm{Gal}$ A plasmid, 550,000 cells per well on six-well plates were cultured. The formulations were diluted in Hank's balanced salt solution and added to the cell cultures. Vectors carrying $2.5 \mu \mathrm{g}$ of DNA were added to each well. Transfection efficacy was quantified at 24 and 72 hours.

\section{$\alpha$-Galactosidase $A$ activity}

A fluorimetric assay for $\alpha$-Gal A determination ${ }^{17}$ was performed. At 24 and 72 hours posttransfection, Hep G2 cells were washed with $600 \mu \mathrm{L}$ of phosphate-buffered saline (PBS), scraped, and collected for centrifugation at $4^{\circ} \mathrm{C}$ and $5000 \mathrm{rpm}$ for 5 minutes. Cell pellets were resuspended in $200 \mu \mathrm{L}$ of Milli-Q water and sonicated. An aliquot was incubated with $5 \mathrm{mM}$ 4-methylumbelliferyl- $\alpha$-D-galactopyranoside in the presence of $100 \mathrm{mM} \mathrm{N}$-acetylgalactosamine (SigmaAldrich), a specific inhibitor of $\alpha$-Gal B activity. ${ }^{18}$ The reaction was stopped 30 minutes later with a $0.2 \mathrm{M}$ glycine buffer ( $\mathrm{pH}$ 10.4). Protein concentrations were determined by a Micro BCA ${ }^{\mathrm{TM}}$ Protein Assay (Thermo Fisher Scientific, 
Waltham, MA). One unit of $\alpha-\mathrm{Gal} A$ activity is equivalent to the hydrolysis of $1 \mathrm{nmol}$ of substrate for 1 hour at $37^{\circ} \mathrm{C}$.

\section{Transfection and cell viability evaluation by flow cytometry}

The transfection efficacy of the vectors containing the pCMS-EGFP plasmid was measured in a FACSCalibur flow cytometer (BD, Franklin Lakes, NJ) as previously described by Delgado et al. ${ }^{15}$ The percentage of EGFPpositive cells was measured at $525 \mathrm{~nm}$ (FL1) and the cell viability at $650 \mathrm{~nm}$ (FL4) after incubation with the BD Via-Probe kit (BD).

\section{EGFP fluorimetric quantitative analysis}

In order to determine the amount of EGFP produced by the Hep G2 cells, a fluorimetric analysis was carried out. Cells were washed once with $400 \mu \mathrm{L}$ of PBS and $200 \mu \mathrm{L}$ of Reporter Lysis Buffer 1X (Promega, Sunnyvale, California) were added. Cells were then scraped and centrifuged at $10,000 \mathrm{rpm}$. An aliquot of the supernatant was employed to measure the fluorescence at $525 \mathrm{~nm}$ in a Glomax Multi+ Detection System (Promega). In order to normalize the results, another aliquot was used to measure the total protein quantity by Micro BCA.

\section{Cellular uptake}

Flow cytometry was also used to quantify the entry of the vectors into the cells by using Nile Red-labeled SLN. ${ }^{10}$ Two hours after the addition of the vectors, the cells were washed three times with PBS and detached from the plates. Nile Red-positive cells were analyzed at $650 \mathrm{~nm}$ (FL4). For each sample, 10,000 events were collected.

\section{Intracellular EMA-labeled DNA detection}

DNA distribution inside the cells was studied by fluorescence microscopy using vectors carrying DNA-EMA, ${ }^{10}$ labeled by drobiosystems. Nuclei were labeled with Hoechst 33258 (Life Technologies). Images were analyzed with an inverted fluorescent microscopy (Eclipse TE2000-S; Nikon Corporation, Tokyo, Japan).

\section{Statistical analysis}

SPSS 19.0 (IBM Corporation, Armonk, NY) was used to carry out the statistical analysis. Shapiro-Wilk and Levene tests were performed to assess the normal distribution of samples and the homogeneity of variance, respectively. A student's $t$-test was applied to compare the different formulations. Statistical significance was set at $P<0.05$.

\section{Results}

\section{Particle size and zeta potential}

Table 1 summarizes the particle size, zeta potential, and polydispersity indices of vectors prepared with or without protamine or protamine and dextran, and either the plasmid pCMS-EGFP or the plasmid pR-M10- $\alpha-$ Gal A. Protamine and dextran did not induce any significant change in DNASLN zeta potential or particle size, irrespective of the plasmid. Moreover, no significant differences in the particle size of vectors prepared with the plasmid pR-M10- $\alpha-G a l$ A at different DNA-to-DOTAP ratios were detected. However, superficial charges of the formulation containing the plasmid pR-M10- $\alpha$-Gal A at a DNA-to-DOTAP ratio of 1:5 was significantly lower $(P<0.05)$ than the surface charge of the vectors prepared with higher DNA-to-DOTAP ratios. The polydispersity index was always lower than 0.4 . When vectors were labeled with Nile Red or EMA for trafficking studies, no changes in particle size or zeta potential were observed.

\section{Binding, DNase I protection, and SDS-induced release of DNA}

All formulations were able to bind all DNA (Figure 1A and B). Both plasmids were protected from DNase I action when formulated with SLN; SLN and protamine; or SLN, protamine, and dextran, except with the formulation containing the pR-M10- $\alpha$-Gal A plasmid at a 1:5 ratio (DNA-SLN) that hardly protected the DNA (Figure 1B, lane 9). The addition of protamine to the formulations increased the DNA

Table I Physicochemical characterization of SLN-based formulations

\begin{tabular}{llll}
\hline Formulation & $\begin{array}{l}\text { Size } \\
(\mathbf{n m})\end{array}$ & PI & $\begin{array}{l}\text { Z-potential } \\
(\mathbf{m V})\end{array}$ \\
\hline PCMS-EGFP-containing vectors & & & \\
DNA-SLN (I:5) & $28 I \pm 13$ & $0.35 \pm 0.03$ & $36 \pm 3$ \\
Protamine-DNA-SLN (2:1:5) & $258 \pm 14$ & $0.35 \pm 0.03$ & $41 \pm 1$ \\
Dextran-protamine- & $267 \pm 12$ & $0.35 \pm 0.03$ & $40 \pm 2$ \\
DNA-SLN (I:2:I:5) & & & \\
pR-MI0- $\alpha G a l$ A-containing vectors & & \\
DNA-SLN (I:5) & $267 \pm 21$ & $0.31 \pm 0.02$ & $12 \pm I^{*}$ \\
DNA-SLN (I:8) & $298 \pm 24$ & $0.31 \pm 0.01$ & $47 \pm 4$ \\
Protamine-DNA-SLN (2:1:5) & $253 \pm 20$ & $0.29 \pm 0.01$ & $39 \pm 4$ \\
Protamine-DNA-SLN (2:I:8) & $278 \pm 22$ & $0.32 \pm 0.02$ & $43 \pm 4$ \\
Dextran-protamine- & $269 \pm 22$ & $0.35 \pm 0.02$ & $39 \pm 3$ \\
DNA-SLN (I:2:I:5) & & & \\
Dextran-protamine- & $306 \pm 21$ & $0.38 \pm 0.02$ & $44 \pm 2$ \\
DNA-SLN (I:2:I:8) & & & \\
\hline
\end{tabular}

Notes: Mean \pm standard deviation $(n=3)$. $* P<0.05$ with respect to the other formulations containing the same plasmid.

Abbreviations: PI, polydisperity index; SLN, solid liquid nanoparticle. 
A

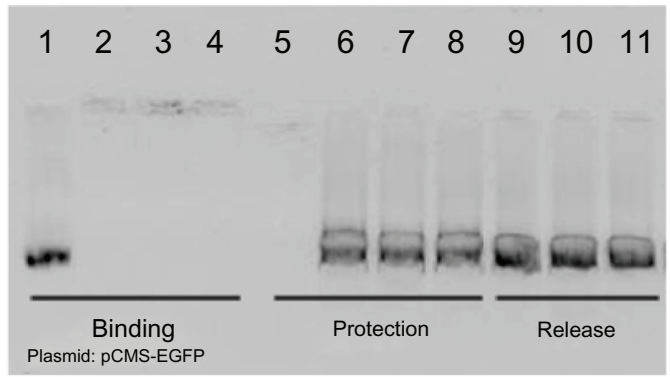

B

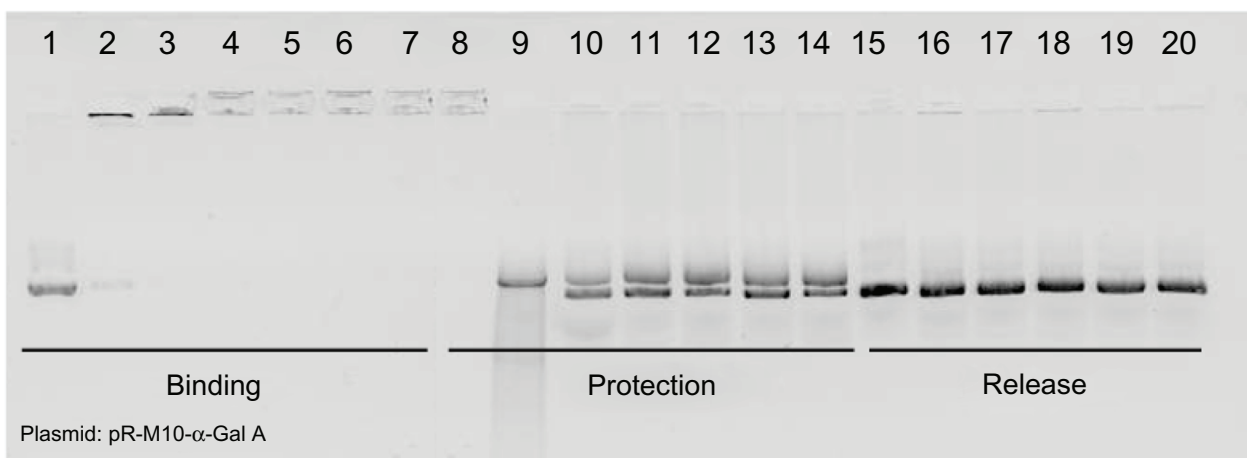

Figure I Binding, protection, and release of DNA with DNA-SLN, protamine-DNA-SLN, and dextran-protamine-DNA-SLN vectors visualized by agarose gel electrophoresis. (A) PCMS-EGFP plasmid: lane I, free DNA (EGFP); lane 2, DNA-SLN vector (I:5); lane 3, protamine-DNA-SLN vector (2:I:5); lane 4, dextran-protamine-DNA-SLN vector (I:2:1:5); lane 5, DNase-treated free DNA; lane 6, DNase-treated DNA-SLN vector (1:5); lane 7, DNase-treated protamine-DNA-SLN vector (2:I:5); lane 8, DNase-treated dextran-protamine-DNA-SLN vector ( I:2: I:5); lane 9, SDS-treated DNA-SLN vector ( I:5); lane I0, SDS-treated protamine-DNA-SLN vector (2: I:5); lane II, SDS-treated dextran-protamine-DNA-SLN vector ( I:2: I:5). (B) pR-MI0- $\alpha$-Gal A plasmid: lane I, free DNA ( $\alpha-G$ al A); lane 2, DNA-SLN vector (I:5); lane 3, DNA-SLN vector (I:8); lane 4, protamine-DNA-SLN vector (2:1:5); lane 5, protamine-DNA-SLN vector (2:I:8); lane 6, dextran-protamine-DNA-SLN vector (I:2:I:5); lane 7, dextran-protamine-DNASLN vector (I:2: I:8); lane 8, DNase-treated free DNA; lane 9, DNase-treated DNA-SLN vector (I:5); lane I0, DNase-treated DNA-SLN vector (I:8); lane I I, DNase-treated protamine-DNA-SLN vector (2:1:5); lane 12, DNase-treated protamine-DNA-SLN vector (2:1:8); lane 13, DNase-treated dextran-protamine-DNA-SLN vector ( I:2:1:5); lane 14, DNase-treated dextran-protamine-DNA-SLN vector (I:2:1:8); lane 15, SDS-treated DNA-SLN vector (I:5); lane I6, SDS-treated DNA-SLN vector ( $: 8$ ); lane I7, SDS-treated protamine-DNA-SLN vector (2:1:5); lane 18, SDS-treated protamine-DNA-SLN vector (2:1:8); lane 19, SDS-treated dextran-protamine-DNA-SLN vector (I:2:1:5); lane 20, SDS-treated dextran-protamine-DNA-SLN vector ( $1: 2: 1: 8)$.

protection capacity. After treatment of the vectors with SDS, DNA was released from all formulations.

\section{$\alpha-$ Galactosidase A activity}

Figure 2 shows the $\alpha$-Gal A activity in Hep G2 cells after treatment with vectors carrying the pR-M10- $\alpha$-Gal A plasmid. The enzymatic activity of the cells treated with

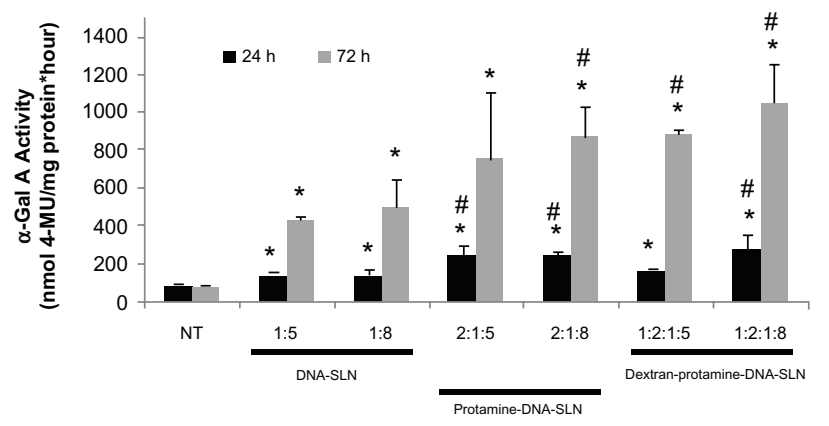

Figure $2 \alpha-$ Gal A activity levels obtained after transfection with vectors containing the pR-MI0- $\alpha$-Gal A plasmid.

Notes: Results were compared to non-treated cells; error bars represent the SD $(\mathrm{n}=3) ;{ }^{*} \mathrm{P}<0.05$ relative to non-treated cells; ${ }^{\#} \mathrm{P}<0.05$ with respect to DNA-SLN formulations. the vectors increased significantly with respect to the untreated cells, regardless of the formulation used. With the protamine-DNA-SLN and dextran-protamine-DNA-SLN vectors, the enzymatic activity levels were significantly higher than those obtained with the DNA-SLN vectors. $\alpha$-Gal A activity increased from $24 \mathrm{~h}$ to $72 \mathrm{~h}$ in all cases except in the untreated cells. No differences in cell viability were found between untreated cells and those treated with the vectors.

\section{Transfection and cell viability studies with vectors containing the pCMS-EGFP plasmid}

When the vectors were prepared with the pCMS-EGFP plasmid, transfection efficacy was evaluated in Hep G2 cells at 24 and 72 hours posttransfection. Figure 3 features the percentage of cells transfected. It can be seen that the presence of protamine in the SLNs produced a significant increase $(P<0.05)$ in the transfection level at every time point. This feature was even higher at 72 hours when dextran was added to the complex. Cell viability did not differ significantly between treated and nontreated cells. 


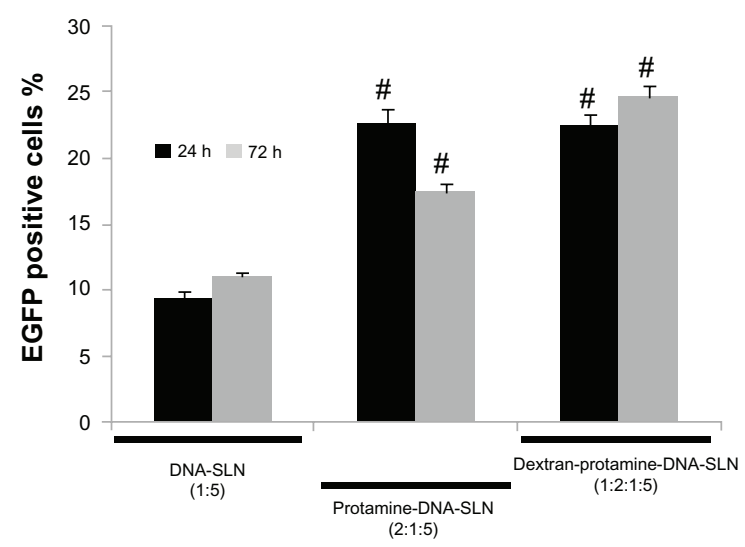

Figure 3 Transfection level of Hep G2 cells after treatment with DNA-SLN ( I:5), protamine-DNA-SLN (2: I:5), and dextran-protamine-DNA-SLN ( I:2: I:5) vectors. Notes: Error bars represent the SD $(n=3)$. ${ }^{\#}<0.05$ relative to DNA-SLN formulation.

Besides quantifying the percentage of transfected cells, the production of EGFP in Hep G2 cells was also measured. Figure 4 shows that EGFP levels increased over time with every formulation assayed. Moreover, the production of EGFP after transfecting the cells with the protamine-DNASLN and dextran-protamine-DNA-SLN vectors was significantly higher $(P<0.05)$ than that produced after transfection with the DNA-SLN vector. Differences were detected at 24 and 72 hours.

\section{Cellular uptake of nonviral vectors}

Figure 5 presents the histograms obtained by flow cytometry where the high entry rate of the vectors into the cell is demonstrated, irrespective of the formulation or the plasmid (pCMS-EGFP or pR-M10- $\alpha-G a l$ A). The presence of protamine or dextran did not vary the entry of vectors carrying the pCMS-EGFP plasmid (Figure 5A). However,

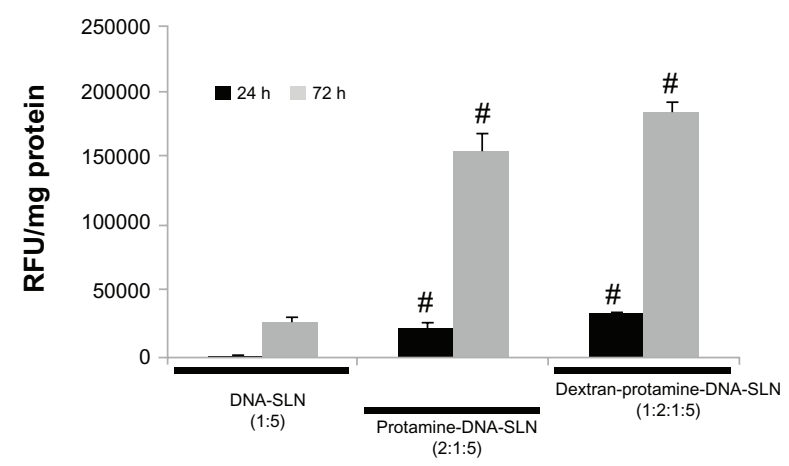

Figure 4 Amount of EGFP produced in Hep G2 cells after treatment with DNA-SLN ( $1: 5)$, protamine-DNA-SLN (2:1:5), and dextran-protamine-DNA-SLN (I:2:1:5) vectors.

Notes: Error bars represent the SD $(n=3)$. ${ }^{\#}<0.05$ relative to DNA-SLN formulation.

Abbreviation: RFU, relative fluorescence unit.

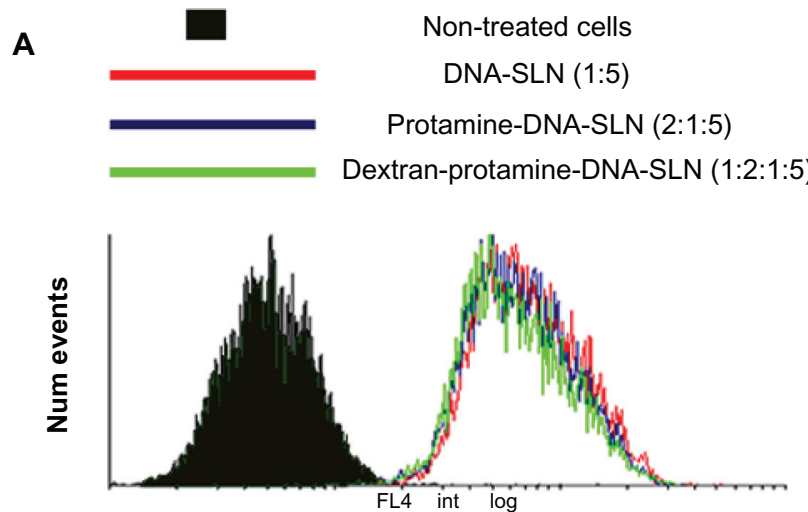

FL 4 Int log

Plasmid: pCMS-EGFP

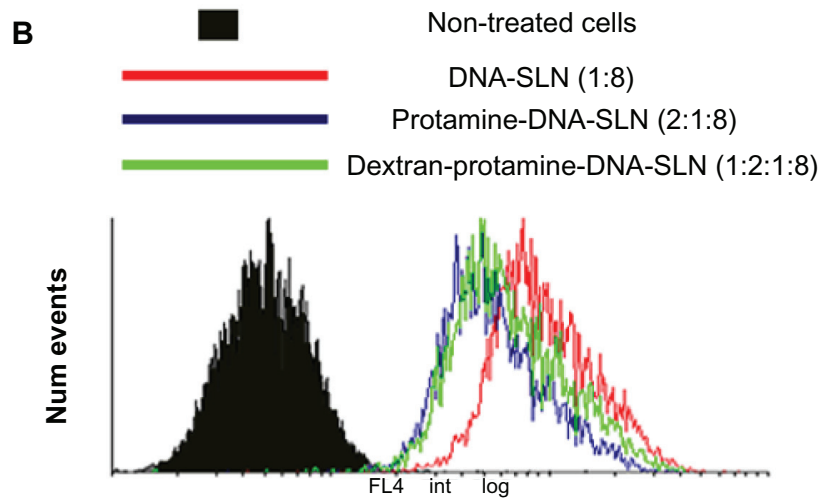

FL 4 Int log

Plasmid: pR-M10- $\alpha$ Gal A

Figure 5 Entry of nonviral vectors in Hep G2 cells 2 hours posttransfection with Nile Red-labeled SLN. (A) Entry of DNA-SLN ( I:5), protamine-DNA-SLN (2:1:5), and dextran-protamine-DNA-SLN (1:2:1:5) vectors carrying the PCMSEGFP plasmid. (B) Entry of DNA-SLN (1:8), protamine-DNA-SLN (2:1:8), and dextran-protamine-DNA-SLN (I:2:1:8) vectors carrying the pR-MI0- $\alpha-G a l A$ plasmid.

when the vectors contained the pR-M10- $\alpha$-Gal A plasmid, the presence of protamine or dextran induced a slight decrease in the internalization, since a higher leftward shift of the histogram is detected in comparison with the DNA-SLN formulation (Figure 5B).

\section{Intracellular distribution of EMA-labeled DNA in culture cells}

Figure 6 presents images captured by fluorescence microscopy at $4 \mathrm{~h}$ after the addition of the vectors containing the EMA-labeled pCMS-EGFP plasmid. When Hep G2 cells were treated with the DNA-SLN vector, red fluorescence appeared homogeneously distributed in the cytoplasm; however, DNA was much more condensed and closer to the nucleus when the cells were treated with protamine-DNASLN and dextran-protamine-DNA-SLN vectors. 


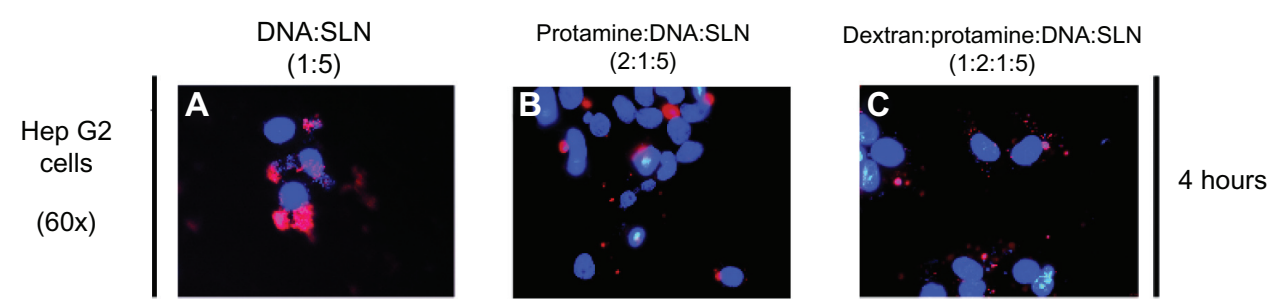

Figure 6 Fluorescence microscopy images of Hep G2 cells after the addition at 4 hours of (A) DNA-SLN, (B) protamine-DNA-SLN, and (C) dextran-protamine-DNA-SLN vectors.

Note: Red coloring shows EMA-labeled DNA and blue coloring cell nuclei stained with Hoechst 33258.

\section{Discussion}

Gene-mediated enzyme replacement is a reasonable and highly promising approach for the treatment of FD. Although many investigators have attempted to treat FD with gene therapy, mainly viral vectors have been used in these studies. ${ }^{7-9,19,20}$ Even though these works provide considerable support for the potential of gene therapy, safety issues are important obstacles to consider when deciding whether to proceed with studies in humans. The present work has revealed the ability of SLNs to increase by means of gene therapy the enzymatic activity of $\alpha$-Gal A in vitro.

Several formulations based on SLNs were prepared, with and without protamine or protamine and dextran. Every formulation studied was able to bind the pR-M10- $\alpha-\mathrm{Gal}$ A plasmid (6916 base pairs) and the pCMS-EGFP plasmid (5500 base pairs). Except for the formulation containing the pR-M10- $\alpha$-Gal A plasmid at a DNA-to-SLN ratio of 1:5 (Figure 1B, lane 9), the rest of the vectors were able to protect DNA from DNase I. The lower protection capacity of this formulation is due to a lower condensation degree of the DNA in the complex, which is more exposed to components in the medium and, thus, the digestion by enzymes becomes easier. The lower condensation degree is confirmed by the lower surface charge. Apart from this, all formulations were able to release the DNA in the presence of SDS. These results emphasize how important it is that the complexes have enough DNA condensation capacity to create an equilibrium between gene protection from DNases and DNA release. ${ }^{14}$

Once the vectors were characterized, we evaluated their capacity to transfect Hep G2 cells, a human hepatocellular carcinoma cell line. Hep G2 cells are well-known models of hepatic parenchymal cells. As previously reported, ${ }^{21}$ enzymes produced in the liver and distributed via the blood are the primary source of enzymes for somatic tissues. Therefore, the liver could be used as a depot organ to produce large amounts of a therapeutic enzyme that will be secreted into the bloodstream and recaptured by other organs..$^{22,23}$
Additionally, Hep G2 cells have been used by other authors as a cell model for Fabry disease to evaluate the intracellular disposition of the $\alpha$-Gal A enzyme. ${ }^{24}$ These are the reasons to employ this cell line to demonstrate the capacity of the vectors to transfect and promote the production of the $\alpha$-Gal A enzyme. In previous studies, we had already shown the ability of SLN-based vectors to efficiently induce transgenic expression in mice livers after intravenous administration. ${ }^{12,16}$

Transfection studies with nanoparticles containing the pR-M10- $\alpha$-Gal A plasmid showed the power of the carriers to induce the expression of the $\alpha$-Gal A enzyme (Figure 2). Seventy-two hours after the administration of the vectors, the enzymatic activity increased up to 12 -fold in comparison with untreated cells depending on the formulation. These results show that the nanocarriers were able to transfect the Hep G2 cells and stimulate the production of the active therapeutic enzyme. On the one hand, $\alpha-G a l A$ activity was similar when the cells were treated with DNA-SLN vectors, in spite of the lower capacity of protection against DNase of the vector prepared with the DNA-SLN ratio of 1:5. It is important to take into account that the impact of the protection capacity against DNases on transfection will be more relevant after in vivo administration. On the other hand, $\alpha$-Gal A activity was significantly higher when cells were treated with the protamine-DNA-SLN and the dextran-protamine-DNA-SLN vectors. Protamine has been widely used in transfection studies due to its high condensation capacity and its ability to translocate DNA molecules from the cytoplasm to the nucleus of living cells..$^{25}$ In a previous study, protamine induced a 6-fold increase in the transfection of SLN in retinal cells. ${ }^{15}$ In the present study, the addition to the protamine-DNA-SLN vector of dextran, a polyanion biocompatible polysaccharide, increased even more the $\alpha$-Gal A activity in vitro. We had previously shown ${ }^{16}$ that the incorporation of dextran in the vector for an in vivo administration in mice induced a longer circulation time of the lipid nanoparticles, probably due to a lower opsonization and a slower uptake by the reticuloendothelial system. These data make protamine-DNA-SLN 
vectors, particularly dextran-protamine-DNA-SLN vectors, promising tools for future in vivo approaches to correct the low $\alpha$-Gal A production in Fabry disease.

Further studies are needed to know the real potential of these new vectors. For instance, the evaluation of the formulation in a Fabry mouse model will allow us to test not only the efficacy of the vector in terms of alpha-GalA production, but also the reduction of Gb3.

Yoshimitsu et $\mathrm{al}^{26}$ transfected a rat cardiomyocytes cell line, $\mathrm{H} 9 \mathrm{c} 2$, with a recombinant lentiviral vector. The level of the increase they obtained in $\alpha-G a l$ A activity with respect to untreated cells was of the same order as that obtained in our study. The same authors, after in vivo administration of the viral vector to a mouse model of Fabry disease, showed that the $\alpha-\mathrm{Gal} \mathrm{A}$ in cardiac tissue rose to $25 \%$ of normal levels by day 7 , which is encouraging because levels of correction approximating $5 \%$ of the normal value may be curative for this disorder. ${ }^{26}$

In order to better know the behavior of the vectors in Hep G2 cells, we performed transfection studies with nanoparticles bearing the pCMS-EGFP plasmid that encodes the green fluorescent protein. In the process of developing new vectors for gene therapy, reporter genes such as EGFP, $ß$-galactosidase, or luciferase plasmids are frequently used since its evaluation, both in vitro and in vivo, is simple and quick. In our case, EGFP expression could be easily measured by flow cytometry and/or fluorimetry in order to determine both the percentage of transfected cells and the amount of protein produced. Transfection of the Hep G2 cells with the vectors bearing the pCMS-EGFP plasmid (Figure 3) revealed that all formulations assayed were able to produce transfection. With the protamine-DNA-SLN and dextran-protamine-DNA-SLN formulations, the percentage of transfected cells was twice that of the DNA-SLN vector $(P<0.05)$.

To further relate the percentage of transfected cells and the level of protein expressed, we also measured the amount of EGFP produced in the transfected Hep G2 cells (Figure 4). We observed that, with every formulation, the EGFP increased over time, with large and significant differences from 24 to 72 hours. Furthermore, EGFP levels were again significantly higher with the protamine-DNA-SLN and dextran-protamine-DNA-SLN formulations in comparison with the DNA-SLN formulation. A 7-fold increase was reached in spite of the fact that the variation in the percentage of cells transfected was only double (Figure 3). These data show that the increase of the number of cells transfected due to addition of protamine or protamine and dextran to the vectors was not proportional to the increase in the amount of the protein produced. Therefore, it is important to note that the measurement of the therapeutic protein and not only the percentage of transfected cells is necessary for the development of these kinds of vectors.

It is known that transfection is conditioned by the entry and intracellular trafficking of the vectors, which are cell line-dependent processes. ${ }^{27,28}$ We studied the cellular uptake of the vectors in Hep G2 cells by means of flow cytometry. No difference in cellular uptake that could justify the differences in cell transfection was found (Figure 5). The intracellular disposition of the transfected genetic material was also analyzed. Figure 6 shows that DNA (red) presents a higher condensation degree when cells were transfected with the carriers prepared with protamine (Figure 6B and C). We also observed this in other cell lines, ${ }^{15}$ which confirms that protamine is an excellent DNA condenser. This feature makes this compound especially effective in reducing the exposition-to-degradation by different cytoplasmic agents, such as DNases, and additionally helps the transport of DNA to the nucleus. Moreover, protamine favors the transport of the complexes into the nucleus due to its content of nuclear localization signals and improves intra-nuclear transcription. ${ }^{29}$ All of these effects of protamine explain the higher percentage of transfected cells and the higher levels of protein produced; in particular, the content of nuclear localization signals of protamine and its effect on the transcription could also explain the high protein production with respect to the percentage of transfected cells.

\section{Conclusion}

This study shows for the first time the ability of a nonviral vector based on SLNs to increase up to 12-fold the $\alpha$-Gal A activity in Hep G2 cells. Moreover, we observed that the percentage of transfected cells was not proportional to the quantity of protein synthesized; this observation has been attributed to the effect of protamine on transcription and also due to the presence of nuclear localization signals in the protamine.

\section{Acknowledgments}

This work was supported by the Basque Government's Department of Education, Universities and Investigation (IT-341-10). We would also like to thank the Basque Government for the research grant awarded to AP Ruiz de Garibay.

\section{Disclosure}

The authors declare no conflicts of interest. 


\section{References}

1. Brady RO, Gal AE, Bradley RM, Martensson E, Warshaw AL, Laster L. Enzymatic defect in Fabry's disease. N Engl J Med. 1967;276(21): 1163-1167.

2. Desnick RJ, Ioannou YA, Eng CM. Alpha-galactosidase A deficiency: Fabry disease. In: Scriver CR, Beaudet Al, Sly WS, Valk D, editors. The Metabolic and Molecular Basis of Inherited Disease. 8th ed. New York: McGraw Hill; 2001:3733-3774.

3. Ramaswami U. Update on role of agalsidase alfa in management of Fabry disease. Drug Des Devel Ther. 2011;5:155-173.

4. Wilcox WR, Linthorst GE, Germain DP, et al. Anti- $\alpha$-galactosidase A antibody response to agalsidase beta treatment: data from the Fabry Registry. Mol Genet Metab. 2012;105(3):443-449.

5. Vedder AC, Linthorst GE, Houge G, et al. Treatment of Fabry disease: outcome of a comparative trial with agalsidase alfa or beta at a dose of $0.2 \mathrm{mg} / \mathrm{kg}$. PLoS One. 2007;2(7):e598.

6. Sands MS, Davidson BL. Gene therapy for lysosomal storage diseases. Mol Ther. 2006;13:839-849.

7. Jung SC, Han IP, Limaye A, et al. Adeno-associated viral vectormediated gene transfer results in long-term enzymatic and functional correction in multiple organs of Fabry mice. Proc Natl Acad Sci USA. 2001;98(5):2676-2681.

8. Takahashi G, Hirai Y, Migita M, et al. Long-term systemic therapy of Fabry disease in a knockout mouse by adeno-associated virusmediated muscle-directed gene transfer. Proc Natl Acad Sci U S A. 2002;99(21):13777-13782.

9. Ogawa K, Hirai Y, Ishizaki M, et al. Long-term inhibition of glycosphingolipid accumulation in Fabry model mice by a single systemic injection of AAV1 vector in the neonatal period. Mol Genet Metab. 2009;96(3):91-96.

10. del Pozo-Rodríguez A, Delgado D, Solinís MA, Gascón AR, Pedraz JL. Solid lipid nanoparticles for retinal gene therapy: transfection and intracellular trafficking in RPE cells. Int J Pharm. 2008;360(1-2):177-183.

11. del Pozo-Rodríguez A, Pujals S, Delgado D, et al. A proline-rich peptide improves cell transfection of solid lipid nanoparticle-based non-viral vectors. J Control Release. 2009;133(1):52-59.

12. del Pozo-Rodriguez A, Delgado D, Solinís MA, et al. Solid lipid nanoparticles as potential tools for gene therapy: in vivo protein expression after intravenous administration. Int J Pharm. 2010;385(1-2): $157-162$.

13. Rodríquez Gascón A, Solinís Aspiazu MA, Del Pozo-Rodríguez A, Delgado San Vicente D, Pedraz Muñoz JL, inventors; Universidad Del Pais Vasco, assignee. Lipid nanoparticles for gene therapy. United States patent 20120183589. July 19, 2012.

14. del Pozo-Rodríguez A, Delgado D, Solinís MA, Gascón AR, Pedraz JL. Solid lipid nanoparticles: formulation factors affecting cell transfection capacity. Int J Pharm. 2007;339(1-2):261-268.

15. Delgado D, Del Pozo-Rodríguez A, Solinís MA, Rodríguez-Gascon A. Understanding the mechanism of protamine in solid lipid nanoparticlebased lipofection: the importance of the entry pathway. Eur J Pharm Biopharm. 2011;79(3):495-502.
16. Delgado D, Gascón AR, del Pozo-RodríguezA, et al. Dextran-protaminesolid lipid nanoparticles as a non-viral vector for gene therapy: In vitro characterization and in vivo transfection after intravenous administration to mice. Int J Pharm. 2012;425(1-2):35-43.

17. Kusiak JW, Quirk JM, Brady RO. Purification and properties of the two major isozymes of alpha-galactosidase from human placenta. J Biol Chem. 1978;253(1):184-190.

18. Mayes JS, Scheerer JB, Sifers RN, Donaldson ML. Differential assay for lysosomal alpha-galactosidases in human tissues and its application to Fabry's disease. Clin Chim Acta. 1981;112(2):247-251.

19. Park J, Murray GJ, Limaye A, et al. Long-term correction of globotriaosylceramide storage in Fabry mice by recombinant adenoassociated virus-mediated gene transfer. Proc Natl Acad Sci U S A. 2003;100(6):3450-3454.

20. Ziegler RJ, Lonning SM, Armentano D, et al. AAV2 vector harboring a liver-restricted promoter facilitates sustained expression of therapeutic levels of alpha-galactosidase $\mathrm{A}$ and the induction of immune tolerance in Fabry mice. Mol Ther. 2004;9(2):231-240.

21. McIntyre C, Byers S, Anson DS. Correction of mucopolysaccharidosis type IIIA somatic and central nervous system pathology by lentiviralmediated gene transfer. J Gene Med. 2010;12(9):717-728.

22. Xu L, Mango RL, Sands MS, Haskins ME, Ellinwood NM, Ponder KP. Evaluation of pathological manifestations of disease in mucopolysaccharidosis VII mice after neonatal hepatic gene therapy. Mol Ther. 2002;6(6):745-758.

23. Mango RL, Xu L, Sands MS, et al. Neonatal retroviral vector-mediated hepatic gene therapy reduces bone, joint, and cartilage disease in mucopolysaccharidosis VII mice and dogs. Mol Genet Metab. 2004;82(1):4-19.

24. Marchesan D, Cox TM, Deegan PB. Lysosomal delivery of therapeutic enzymes in cell models of Fabry disease. $J$ Inherit Metab Dis. 2012;35:1107-1117.

25. Biegeleisen $\mathrm{K}$. The probable structure of the protamine-DNA complex. J Theor Biol. 2006;241(3):533-540.

26. Yoshimitsu M, Higuchi K, Dawood F, et al. Correction of cardiac abnormalities in fabry mice by direct intraventricular injection of a recombinant lentiviral vector that engineers expression of alphagalactosidase A. Circ J. 2006;70(11):1503-1508.

27. Li W, Ishida T, Tachibana R, Almofti MR, Wang X, Kiwada H. Cell type-specific gene expression, mediated by TFL-3, a cationic liposomal vector, is controlled by a post-transcription process of delivered plasmid DNA. Int J Pharm. 2004;276(1-2):67-74.

28. von Gersdorff K, Sanders NN, Vandenbroucke R, De Smedt SC, Wagner E, Ogris M. The internalization route resulting in successful gene expression depends on both cell line and polyethylenimine polyplex type. Mol Ther. 2006;14(5):745-753.

29. Masuda T, Akita H, Harashima H. Evaluation of nuclear transfer and transcription of plasmid DNA condensed with protamine by microinjection: the use of a nuclear transfer score. FEBS Lett. 2005;579(10): 2143-2148.
Drug Design, Development and Therapy

\section{Publish your work in this journal}

Drug Design, Development and Therapy is an international, peerreviewed open-access journal that spans the spectrum of drug design and development through to clinical applications. Clinical outcomes, patient safety, and programs for the development and effective, safe, and sustained use of medicines are a feature of the journal, which

\section{Dovepress}

has also been accepted for indexing on PubMed Central. The manuscript management system is completely online and includes a very quick and fair peer-review system, which is all easy to use. Visit $\mathrm{http}: / /$ www.dovepress.com/testimonials.php to read real quotes from published authors. 